African Crop Science Journal by African Crop Science Society is licensed under a Creative Commons Attribution 3.0 Uganda License. Based on a work at www.ajol.info/ and www.bioline.org.br/cs DOI: https://dx.doi.org/10.4314/acsj.v28i4.4

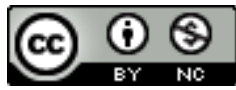

\title{
ENDOPHYTIC FUNGI FOR BIOLOGICAL CONTROL OF WHITEFLY AND TOMATO LEAF MINER IN TANZANIA
}

\author{
G. MICHAEL, A.M.S. NYOMORA, E.F. MVUNGI and E.M. SANGU
}

Department of Botany, University of Dar es Salaam, P. O. Box 35060, Dar es Salaam, Tanzania Corresponding author:mimigabu@gmail.com

(Received 13 July 2020; accepted 2 November 2020)

\begin{abstract}
Tomato whiteflies (Bemisia tabaci) and leaf miners (Tuta absoluta) are devastating pests of tomato (Lycopersicon esculentum). Pest management using broad spectrum synthetic pesticides is discouraged due to harmful effects on human health and the environment. The objective of this study was to assess the potential of endophytic fungi as bioextracts against tomato whiteflies and leaf miners, as an alternative to synthetic insecticides in Tanzania. The study was done using morphological and molecular techniques, during January 2019 to February 2020 in Arusha region in Tanzania. Three endophyte isolates from pyrethrum (Chrysanthemum cinerariifolium) and lemon grass (Cymbopogon citratus) were identified with resemblance to members of Fusarium sp and Altenaria sp, by 90 and 82 $\%$ similarity, respectively; based on phylogenetic clustering patterns and macro- and micromorphological characteristics. Bioextracts from endophytes of lemon grass leaves (Elg1); and pyrethrum flowers (Epf1) and leaves $\left(\right.$ Epl1), showed significant repellency properties $\left(\mathrm{F}_{0.05}(\mathrm{df}, 15)=\right.$ $27.052, \mathrm{P}=0.0001$ ) on whiteflies by 54,76 and $36 \%$, respectively. They also caused significant lethality $\left(\mathrm{F}_{0.05}(\mathrm{df}, 11)=59.559, \mathrm{P}=0.0001\right)$ of tomato leaf miner larvae and whiteflies $\left(\mathrm{F}_{0.05}(\mathrm{df}, 11)=53.600, \mathrm{P}=\right.$ 0.0001 ). The underlying effect was attributed to possession of flavonoid and total phenolics as active ingredients in the bioextracts. This was commensurate to the levels flavonoid and total phenolic contents, which were considerably more in bioextracts of lemon grass and pyrethrum flower (F0.05 (df, $8)=10.35, \mathrm{P}=0.0114)$ and $(\mathrm{F} 0.05(\mathrm{df}, 8)=40.84, \mathrm{P}=0.0003$, respectively $)$, than in pyrethrum leaves.
\end{abstract}

Key Words: Bemisia tabaci, flavonoid, Lycopersicon esculentum, Tuta absoluta

\section{RÉSUMÉ}

Les aleurodes de la tomate (Bemisia tabaci) et les mineuses de la tomate (Tuta absoluta) sont des ravageurs dévastateurs de la tomate (Lycopersicon esculentum). La lutte antiparasitaire utilisant des pesticides synthétiques à large spectre est déconseillée en raison des effets nocifs sur la santé humaine et l'environnement. L'objectif de cette étude était d'évaluer le potentiel des champignons endophytes comme bio extraits contre les aleurodes de la tomate et les mineuses de la tomate, comme alternative aux insecticides synthétiques en Tanzanie. L'étude a été réalisée à l'aide de techniques 
morphologiques et moléculaires, de Janvier 2019 à Février 2020 dans la région d'Arusha en Tanzanie. Les trois isolats d'endophytes de pyrèthre (Chrysanthemum cinerariifolium) et de citronnelle (Cymbopogon citratus) ont été identifiés avec une ressemblance avec des membres de Fusarium sp et Altenaria sp, par 90 et $82 \%$ de similitude, respectivement; basé sur des schémas de regroupement phylogénétique et des caractéristiques macro et micro morphologiques. Bio extraits d'endophytes de feuilles de citronnelle (Elg1); et les fleurs de pyrèthre (Epf1) et les feuilles de pyrèthre (Epl1), ont montré des propriétés répulsives significatives $\left(\mathrm{F}_{0,05}(\mathrm{df}, 15)=27,052, \mathrm{P}=0,0001\right)$ sur les aleurodes de 54,76 et $36 \%$, respectivement. Ils ont également causé une létalité significative $\left(\mathrm{F}_{0,05}(\mathrm{df}, 11)=59,559\right.$, $\mathrm{P}=0,0001)$ des larves de mineuses de la tomate et des aleurodes $\left(\mathrm{F}_{0,05}(\mathrm{df}, 11)=53,600, \mathrm{P}=0,0001\right)$. L'effet sous-jacent a été attribué à la possession de flavonoïdes et de composés phénoliques totaux en tant qu'ingrédients actifs dans les bioextraits. Cela était proportionnel aux teneurs en flavonoïdes et phénoliques totales, qui étaient considérablement plus élevées dans les bioextraits de citronnelle et de fleur de pyrèthre $\left(\mathrm{F}_{0,05}(\mathrm{df}, 8)=10,35, \mathrm{P}=0,0114\right)$ et $\left(\mathrm{F}_{0,05}(\mathrm{df}, 8)=40,84, \mathrm{P}=0,0003\right.$, respectivement $)$, que dans les feuilles de pyrèthre.

Mots Clés: Bemisia tabaci, flavonoïde, Lycopersicon esculentum, Tuta absoluta

\section{INTRODUCTION}

Endophytes are microorganisms that colonise localised or systemic internal plant tissues, and initiate ecological associations that range from mutualism to commensalism, without showing macroscopic disease symptoms (Kumar and Kaushik, 2013). Endophytes comprise reliable sources of genetic diversity that can be utilised outside their dominant host plants. Evidence attests that endophytes help to reduce plant pests attack, herbivorous deterence and pathogen multiplication; by production of secondary metabolites that enhance host plant resistance, increase pests or pathogen toxicity and herbivorous deterrence (Faeth and Fagan, 2002). Endophytes also have ability to secret bioactive compounds in their liquid growth media that can suppress growth of other organisms; while helping the endophytes shrive under stress conditions.

Many studies have been done on endophytic diversity, ecology and biotechnological applications on grasses, woods and some crops; and recently on crops of the tropics (Athman et al., 2007; Bogner et al., 2015). The overall results indicate that endophyte infested-plants are more resistant to pathogenic insect pests, pathogens and herbivorous than uninfected plants (Nisa et al., 2018). There is also evidence of possibilities of isolating endophytic fungi from various host plants, utilised directly as entomopathogens; or indirectly by using their secreted bioactive chemicals in bioextracts controlling insect pests and reduce plant pathogens (Clement $e t$ al., 2005). An example is the isolation of endophytic fungi Beauveria bassiana from maize, potatoes and tomato used effectively to control European maize borer (Ostrinia nublialis), and grasshoppers and locusts (McKinnon et al., 2017).

Plants such as pyrethrum (Chrysanthemum cinerarifolium) and lemon grass (Cymbopogon citratus) are known as pesticidal plants for their ability to produce secondary metabolites, with several bioactive compounds that deter or kill insect pests. Pinto et al. (2015) analysed monoterpenoids and sesquiterpenoid compounds in essential oil of lemongrass, and found the biochemical compounds to have strong organoleptic properties. Shawkat et al., (2011) described secondary metabolites of pyrethrum as phyrethrin, which is a mixture of six active compounds, namely pyrethrin I and II, cineren I and II, Jasmolin I and II. All the aforementioned secondary metabolites are renowned to possess pesticidal properties in some insect pests (Grdiša and Gršiæ , 2013).

Different studies on endophytes and their bioextracts of pesticidal plants have been conducted world-over, with a diversity of 
promising biocontrol results (Nair and Padmavathy, 2014; Avinash and Krishnamurthy, 2015). Studies in South Africa, Uganda and Kenya reported marked progress in pests management using endophytic fungi and their bioextracts. Presently, however, there is no information to the effect that endophytes fungi from pyrethrum and lemon grass can control pests like white flies and leaf miners of tomato under African conditions. Therefore, the objective of this study was to assess the potential of endophytic fungi as bioextracts against dominant tomato whiteflies and leaf miners, as an alternative to synthetic insecticides in Tanzania.

\section{MATERIALS AND METHODS}

This study was conducted at Tengeru Horticulture Research Institute (HoRTITengeru) farm, located in Meru District, Arusha Region in Tanzania ( $36^{\circ} 45^{\prime}$ and $37^{\circ} 00^{\prime}$, $03^{\circ} 15^{\prime}$ and $03^{\circ} 30^{\prime} \mathrm{S}$; at $1290 \mathrm{~m}$ above sea level). The area receives annual rainfall of $1,085 \mathrm{~mm}$, on clay soil texture of $\mathrm{pH} 6.0-6.7$ ( Njau et al., 2017).

Tomato (Lycopersicon esculentum), variety cv Tanya (LBR 11) was the study crop; while the sources of endophytes were pyrethrum $(C$. cinerarifolium) and lemon grass $(C$. citritus) collected from neighborhood fields, by vegetative propagation. Fifteen fragments (approximately $7 \mathrm{~cm}$ ) of the parent lemon grass (leaf stalks) and pyrethrum plant were obtained from farmer fields near the HORTTengeru in Meru District, and transplanted in beds of $15 \mathrm{~m} \mathrm{x} 2 \mathrm{~m}$ each. The beds were located on open space, (planted in situ) to expose the plant to natural stimulus like sun, fertile soil, biotic stress and in area close to water channel. The sample materials were collected six months later (in July 2019), from matured leaves and flowers of pyrethrum and lemon grass.

Plant materials sampling. Healthy plant parts with uniform colouration, upright appearing, open and vigorous growth leaves and matured flowers from pyrethrum and lemon grass were collected from previous transplanted plants from Horticulture field - Tengeru, Meru District, Tanzania and kept separately in labeled paper envelops. They were temporarily stored in cool boxes $\left(4^{\circ} \mathrm{C}\right)$ before being transferred to the laboratory for further processing.

Isolation of endophytic fungi. The endophytic fungi were isolated from the study plants using the direct extraction method described by Nisa et al. (2018). Plant parts were cleaned using running tap water for at least 5 minutes, and surface sterilised with $70 \%$ ethanol for two minutes. Then, they were deeped into $3 \%$ sodium hypochlorite for 3 minutes, and finally rinsed three times in distilled water. The samples were blotted with a sterile paper towels to dry under a laminar floor hood.

The samples were then sliced using sterile razor blades into small pieces (approximately $5 \mathrm{~m} \times 10 \mathrm{~mm}$ ), and placed on potatoes dextrose agar (PDA) culture media, before being incubated at $27{ }^{\circ} \mathrm{C}$ for 7 days. Thereafter, a pure culture was prepared from single spore culture. The isolated endophytes were then identified using both morphological and molecular approaches.

Morphological identification of isolates. Macro-morphological characteristics were assessed according to Singh et al. (1991) based on colony characteristics, namely medium colour changes, mycelium characteristics, fruiting/spore structures and marginal characteristics. Micro-morphological characteristics were assessed by plucking small fragments $(2 \mathrm{~mm})$ of cultured endophytes, using inoculating needles and placed on clean glass slides. The slides were stained using Lactophenol cotton blue (lcb), and observed under light microscope (Olympus Bx51, Tokyo, Japan) as described by Nisa et al. (2018). 


\section{Molecular identification}

DNA extraction. Total genomic DNA was extracted directly from pure endophytic cultures, using cationic detergent cetyltrimethyl ammonium bromide (CTAB) method and sterile sea sands in cell lysis as done by Yee et al. (2018). Briefly, $150 \mathrm{mg}$ of mycelium were placed into sterilised $1.5 \mathrm{ml}$ Eppendorf tube containing $300 \mu \mathrm{l}$ of TES extraction buffer and acid-washed, sterilised sea sand. The samples were vortexed for 30 seconds and then addition of $250 \mu \mathrm{l}$ of TES extraction buffer containing proteinase $\mathrm{K}$ were performed, and vortex thoroughly and incubated in $65^{\circ} \mathrm{C}$ water bath for 30 minutes. Then, $200 \mu \mathrm{l}$ of $7.5 \mathrm{M}$ of ammonium acetate were added and incubated for 10 minutes at $5{ }^{\circ} \mathrm{C}$ under refrigeration; and centrifuged at 20,800 g for 15 minutes.

The supernatant was transferred into tubes and equal volumes $(500 \mu \mathrm{l})$ of ice cold isopropanol added, and incubated in freezer at $-20{ }^{\circ} \mathrm{C}$ for 2 hours. The samples were centrifuged at 20,800 $\mathrm{g}$ to pellet the DNA.

The supernatant was decanted and DNA pellets washed twice with $800 \mu \mathrm{l}$ of cold $70 \%$ ethanol. The tubes were turned upside down on clean sterile paper towels for 15 minutes to allow DNA pellet to dry. The DNA was eluted from the pellet twice with $50 \mu \mathrm{l}$ of $1 \mathrm{x}$ TE buffer.

DNA solution was transferred to $1.5 \mathrm{ml}$ micro-centrifuge tubes and $5 \mu$ of RNase (20 $\mathrm{mg} \mathrm{ml}^{-1}$ ) were added and incubated at $37{ }^{\circ} \mathrm{C}$ for 60 minutes. The DNA was recovered and air-dried as described above. The concentration and purity of DNA were determined by Nanodrops AE-Nano200 Nucleic Acid Analyser version 2.0 and was recorded in ng/Il. The purity of DNA was based on the ratio of optical density (OD) at the wavelength of 260 and $280 \mathrm{~nm}$.

Polymerase chain reaction. The DNA fragment (ITS rDNA) was ampliûed in an automated thermal cycler (TM Cycler BIO-
RAD). Ampliûcation was performed with primers ITS1 (TCCGTAGGTGAACCTGC GG -forward) and ITS4 (TCCTCCGCTT ATTGATATGC-reverse), in a $50 \mu$ reaction volume; which contained PCR buffer $(10 \mathrm{mM}$ $\mathrm{KCl}, 10 \mathrm{mM}\left(\mathrm{NH}_{4}\right)_{2} \mathrm{SO}_{4}, 20 \mathrm{mM}$ Tris- $\mathrm{HCl}, \mathrm{pH}$ $8.8,0.1 \%$ Triton X-100), $1.5 \mathrm{mM} \mathrm{MgCl}, 200$ $\mu \mathrm{M}$ of each deoxyribonucleotide triphosphate, 15 moles of each primer, $100 \mathrm{ng}$ template DNA, and 2.5 units of Taq DNA polymerase.

The thermal cycling programme was as follows: initial denaturation at $95{ }^{\circ} \mathrm{C}$ for 3 minutes, followed by 35 amplification cycles at $92{ }^{\circ} \mathrm{C}$ for 1 minutes for denaturation, $50{ }^{\circ} \mathrm{C}$ for 1 minutes for annealing, $72^{\circ} \mathrm{C}$ for 2 minutes for extension $72{ }^{\circ} \mathrm{C}$ for 10 minutes for final extension as method as done by Deepthi et al. (2018). Following amplification, the PCR products were verified by agarose gel electrophoresis made by $2 \%$ agarose gel supplemented with ethidium bromide. The PCR products were sequenced at INQABA laboratory in South Africa, using same primers.

Phylogenetic analysis. The sequence contigs were aligned with the ClustalX programme in FASTA format. They were then assembled, trimmed and matched with the GenBank nucleotide database, with the Basic Local Alignment Search Tool (BLAST) in Geneious Prime 2020 bioinformatics software platform (Tanney and Seifert, 2020). The sequence contigs in FAST A format were imported to MEGA 6.0 programme for reconstruction of phylogenetic relationships of the endophytic fungi. The Neighbor-Joining (NJ) phylogenetic tree was constructed from an evolutionary distance by MEGA 6.0 software.

Bio-extract secretion. Pure cultures of endophytes were prepared in $250 \mathrm{ml}$ Erlenmeyer flasks with potato dextrose broth (PDB), for eight weeks in a dark room and without shaking. This was done to obtain bioextracts that would be used to quantify biochemical contents, test for insect repellence and insecticidal properties. 
Tests for repellency properties. Trials for testing repellency for bioextracts were made from pure culture of endophytic fungal isolates from pyrethrum leaves, flowers and lemon grass leaves coded Epl, Epf and Elg. The aforementioned endophytes (Epl, Epf and Elg) were cultured on Potato Dextrose Broth and left for bioextract secretion that were coded $\mathrm{Bpl}, \mathrm{Bpf}$ and Blg, respectively.

Fifty whiteflies (B. tabaci) were released into a compartment containing 8 potted tomato plants, arranged in four groups of two plants each (Fig. 1). Each set of two plants was treated with bio-extracts prepared from pyrethrum leaves (BPL) and flowers (BPF), and lemon grass (BLG). The remaining two plants were treated with sterile distilled water, to serve as control treatment. The set of treatments was replicated four times and the numbers of white flies present on tomato plants recorded for 12 hours at an interval of 3 hours.

Lethal effects of bio-extracts. Endophytic fungal bioextracts were tested for lethal effect against white flies and tomato leaf miner, according to the method optimised by Sinthusiri and Soonwera (2013). The trial involved releasing 20 whiteflies into four separately covered potted tomato plants, sprayed with $15 \mathrm{ml}$ of the bioextracts. Each category of bio-extract was used to spray one plant and distilled water on another plant, the latter serving as a control. The experiment was replicated three times and the number of live whiteflies was recorded after 12 hours.

Testing of the lethal effect of the bioextract against tomato leaf miner larvae involved spraying $10 \mathrm{ml}$ each category of endophytic fungal bioextract on three petri dishes, containing two tomato leaves each. The control treatment was prepared similarly, by spraying $10 \mathrm{ml}$ distilled water on petri dishes containing two tomato leaves. The four petri dishes were covered separately with agro-net and left to dry for one hour. Thereafter, twenty tomato leaf miner larvae were introduced in petri dishes, in a set up replicated 3 times. The number of live tomato leaf miner larvae was recorded after 12 hours.

\section{Phenolic and flavonoids contents of} bioextracts. The bioextracts were filtered through sterilised Whatman filter paper no. 44, before the filtrates were extracted three times with equal volumes of ethyl acetate $(20 \mathrm{ml})$ using the liquid - liquid partition method as described by Kumar and Kaushik (2013). The solvent was blended and concentrated in a lamina flow hood, at room temperature (25

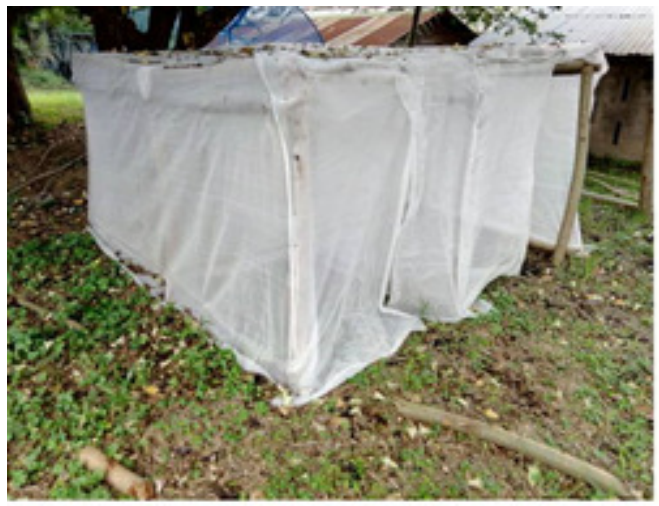

A

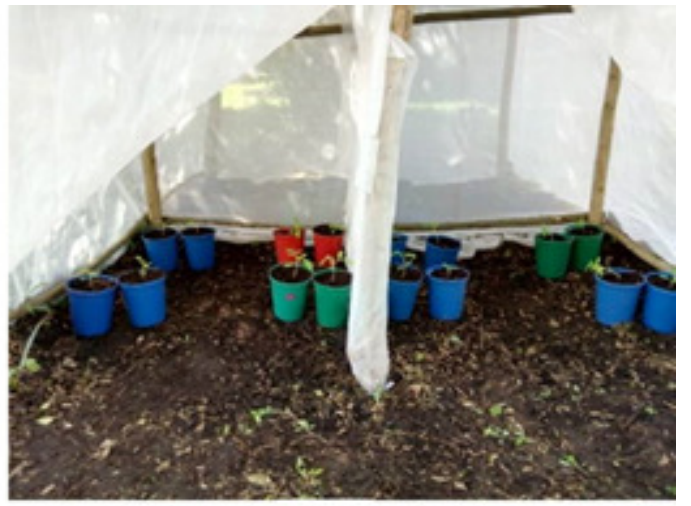

B

Figure 1. Experimental layout for testing repellency activity of bio-extract made from Pyrethrum leaves and flowers, and lemon grass leaves. (A) Completely covered compartments, (B) arrangement of 8 potted plants in a compartment. 
${ }^{\circ} \mathrm{C}$ ) for three days. Then, the dried crude samples were dissolved in methanol and used for quantification of total phenolic and flavonoids, using spectro photometer BioTec Multireader model ELX808.

The flavonoid contents of the bioextracts from various endophytes were analysed in terms of quercetin equivalent, using a standard equation.

$\mathrm{Y}=0.172 \mathrm{x}-0.249$ Equation 1

Where:

$\mathrm{Y}=$ Measured optimal optical density values from each sample; and $\mathrm{x}=$ Equivalent flavonoid concentration.

Also, the total phenol contents of various bioextracts secreted by selected endophytes were assessed by Folin-Ciocalteu reagent in terms of gallic acid equivalent using a standard equation:

$Y=0.128 x-0.106$ Equation 2

Where:

$\mathrm{Y}=$ Measured optimal optical density values from each sample, and $\mathrm{x}=$ Equivalent phenolic concentration.

Data analysis. Fungal colonies and morphological characteristics, nucleotide sequence data analysis for lineage relationship based on distance methods with neighbour joining algorism, were used to resolve the different endophyte isolates into respective taxonomic groups. One-way analysis of variance was used to test for significant variations of the effects of various treatments on repellence or lethality of the bioextracts prepared from different isolates of fungal endophytes.

The study also utilised one-way analysis of variance to test for significances different between quantity of flavonoid and total phenol on different endophytic bioextracts secreted by selected isolated endophytic fungi. Tukey-
Kramer Multiple Comparisons test was used as post-hoc test for mean comparison.

\section{RESULTS}

Morphological identification. Endophytic fungi from pyrethrum (Epl and Epf1) and lemon grass fungi (Elg1) grew fast with sufficient colonisation frequencies on potatoes dextrose agar (PDA) (Fig. 2). All isolates were whitish in the early stages, but changed to grey and greyish green for Epl1 and Elg1 in the later stages, respectively. On the contrary, Epf1 retained its whitish colour up to late stages.

Textures were smooth at the early stage, but rough later with cottony mycelium. Conidia varied in size, forming macro- and microconidia with the largest conidia sized 13-16 $\mu \mathrm{m}$ (Elg1 isolates). The shape ranged from sickle-shaped that are septate, fusoid to obpyriform shaped. The colour of the colonies' on the reverse side of the PDA media, turned from colourless to light brownish colour (Fig. 2 and Table 1).

\section{Molecular identification of endophytic}

fungi. Electrophoresis analysis of fragments of total genomic DNA amplified on the PCR, indicated that the isolates, Elg1, Epl1 and Epf1, produced band sizes of approximately 550 base pair (bp) (Fig. 3). Analysis of the ITS sequences of the Elg1, Epl1 and Epf1 endophytic fungal isolates by matching with the available sequences in the NCBI sequence database, revealed that the isolates were closely related to five fungal species of the Division Ascomycota.

In all the ITS sequence subjected to blast search in the NCBI sequence database, none of the sequences matched perfectly with reference strains in NCBI. Therefore, only the sequences with percentage query coverage of more than 80 , and percentage identity of more than 80 , were considered as close related morpho-species on each clade (Table 2).

The phylogenetic analyses of the aligned sequences of the isolates, subjected to neighbor-Joining (NJ) analysis, and primarily 


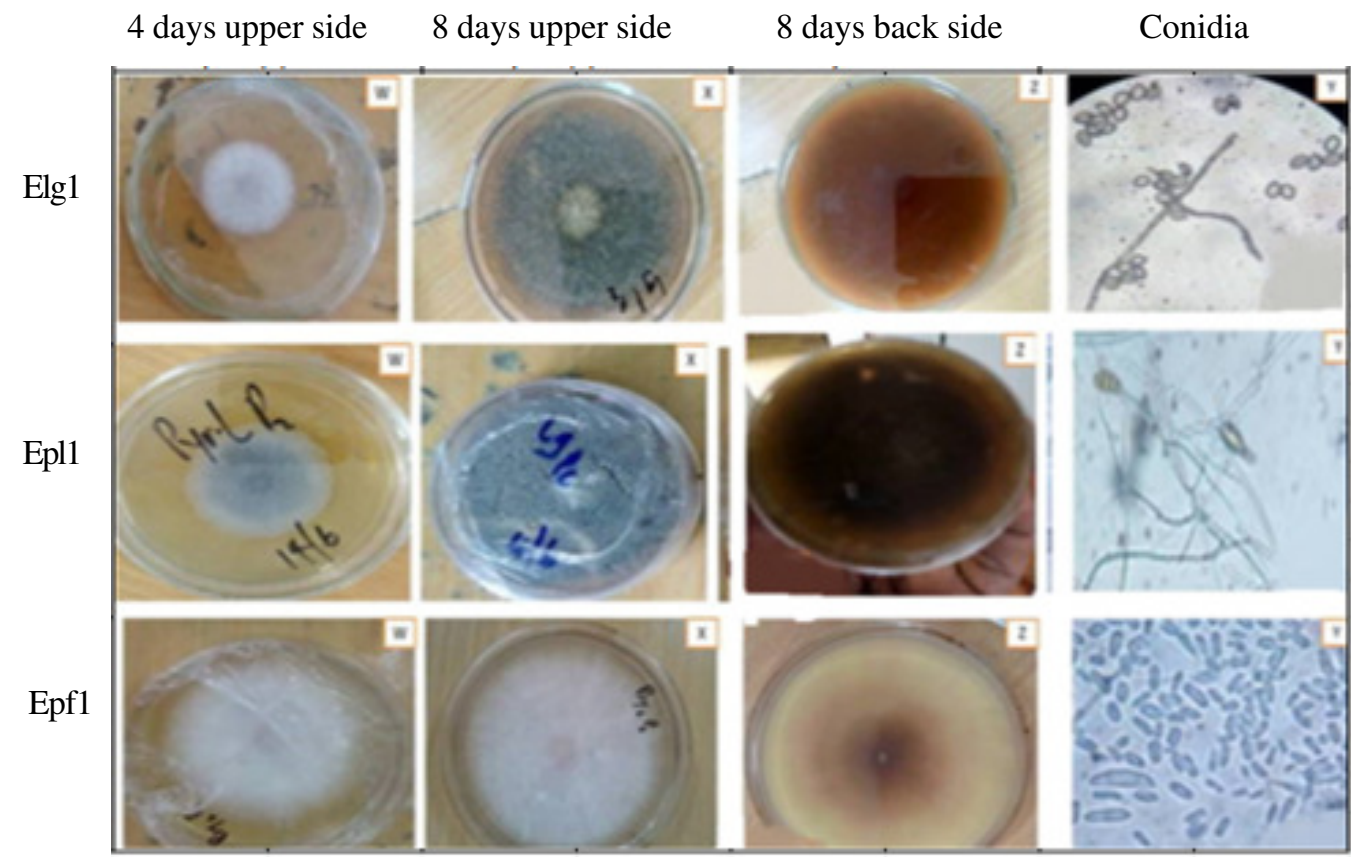

Figure 2. Morphology (colony appearance, hypha and conidia) of endophytic fungal isolates after 4 days $(\mathrm{W})$, and 8 days $(\mathrm{X})$ upper side and reverse side $(\mathrm{Z})$, conidia $(\mathrm{Y})$ (x100 magnification).

grouped all isolates and their close related species into two major clusters A and B (Fig. 4). Major cluster B contained strains: Elg1 and $F$. verticillioides; and major cluster $\mathrm{A}$ consisted of two groups, namely groups 1 and 2. Group 1 consisted of the two strains of Alternaria sp. (A. alternate, A. arborescence) and Epl1; while group 2 consisted of the two strains of Fusaria sp. (F. oxysporum, F. venenatum). and of isolates Epf1. The phylogenetic analysis of the aligned sequences using neighbour-Joining (NJ) analysis produced a tree dendrogram, with five clade (morphospecies) of the filamentous ascomycete's species (Fig. 4).

Repellant and lethal effects of endophytes. Table 3 summarises the results of the number of whiteflies that were deterred by endophyte bioextracts, and surviving tomato leaf miners; and whiteflies on tomato seedlings sprayed with bioextracts from different endophyte isolates (Fig. 1). There was significant variation in the repellency effects among the different bioextract treatments $\left(\mathrm{F}_{0.05}(\mathrm{df}, 15)=27.052\right.$, $\mathrm{P}=0.0001)$, compared to the control.

Lethal tests of whiteflies (B. tabaci) and tomato leaf miner ( $T$. absoluta) showed very few survivors in sprayed samples after twelve hours, compared to the control trial. There was also a significant variation $\left(\mathrm{F}_{0.05}(\mathrm{df}, 11)=\right.$ $59.559, \mathrm{P}=0.0001)$ of live number of $T$. absoluta and $\left(\mathrm{F}_{0.05}(\mathrm{df}, 11)=53.600, \mathrm{P}=\right.$ 0.0001 ) of live number of $B$. tabaci between the control and bioextract of pyrethrum leaves with number live $T$. absoluta and B. tabaci on sprayed samples by bioextracts of lemon grass and pyrethrum flower (Table 3 ).

Phenolics and flavonoids in bio-extracts.

The results of flavonoid content in bioextracts, Bpf1, Bpl1 and Blg1, were 11.4 $\pm 0.9,8.4 \pm 1$ and $16.8 \pm 3 \mathrm{mg} \mathrm{g}^{-1}$ for ethyl acetate extractions, respectively (Table 4). For flavonoid content, lemon grass and phyrethrum flower bioextracts had significantly greater $\left(\mathrm{F}_{0.05}(\mathrm{df}, 8)=10.35, \mathrm{P}=0.0114\right)$ flavonoid contents than those in pyrethrum leaves. 
Total phenol content from bioextracts, Bpf1, Bpl1 and Blg1, was 48.01 $\pm 2.0,135.22$ \pm 3.7 and $46.01 \pm 1.3 \mathrm{mg} \mathrm{g}-1$ in the ethyl acetate extractions, respectively. Based on this parameter, lemon grass bio-extracts had significantly more $\left(\mathrm{F}_{0.05}(\mathrm{df}, 8)=40.84, \mathrm{p}=\right.$ 0.0003 ) total phenolic contents than did pyrethrum flowers and leaves (Table 4).

\section{DISCUSSION}

Morphological identification. All the studied endophytes from pyrethrum and lemon grass, based on number of endophytes grown in cultured plant segments, showed sufficient colonisation frequencies, during fungal isolation (Table 1). The higher the colonisation frequency, the greater was the dominance of endophytes in plant part. It is, therefore, presumed that dominance of a particular endophytes in a specific plant, in specific area, makes that endophyte more available for useers in that area.

More recurring endophytes were observed in mature parts of pyrethrum and lemon grass (Fig. 2). Using comparison of microscopic and macroscopic morphological characteristics with those illustrated by the Mycological Manual (Singh et al. (1991), the endophytes were identified as Fusaria verticillioides, Alternaria alternate and Fusaria chlamydosporum. The characteristics of all individuals were visible in early and late stages, and in micro- and macro-scopic view (Table 1, Fig. 2).

The results of this study concurs with the study of Avinash and Krishnamurth (2015) that showed that out of 2000 samples of lemon grass endophytic, Fusarium sp. and Curvularia sp. were frequently isolated more than others endophytes. Elgorban et al. (2019) also showed Alternaria sp. as the prospective endophytic fungi from Salvadora persica for the production of bioactive compounds against pathogenic bacteria and fungi. Therefore, endophyte isolates obtained from these plants (pyrethrum and lemon grass) are considered as Fusaria sp. and Alternaria sp. based on 


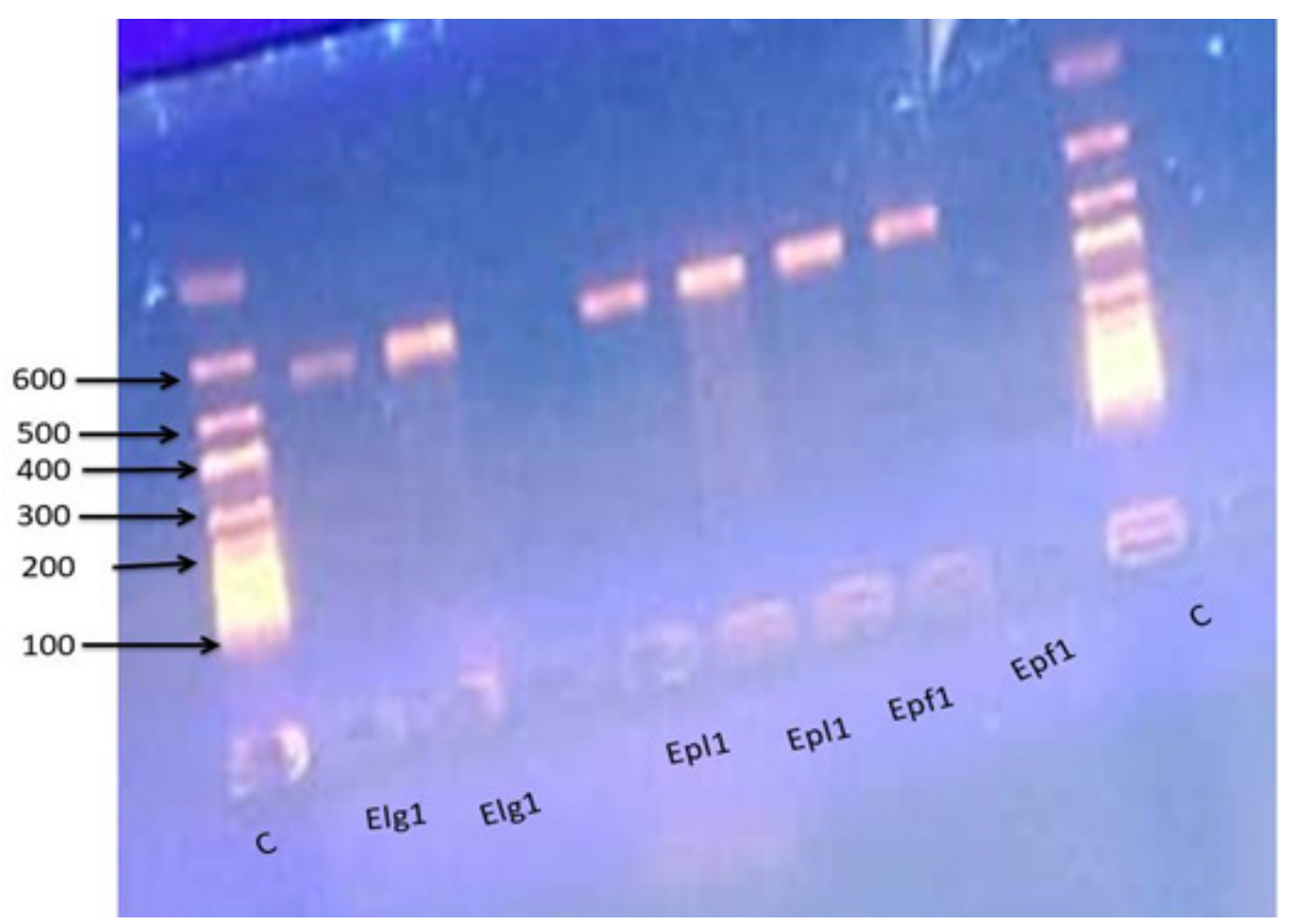

Figure 3. PCR amplification of Elg1, Epl and Epf1 isolates run on 2\% agarose gel, at 100 volts, 30 mins. $\mathrm{C}$, represents the marker.

TABLE 2. NCBI Blast results using Geneious Prime 2020 bioinformatics software platform

\begin{tabular}{llccc}
\hline Isolate code & Species name & $\begin{array}{c}\text { Identity } \\
(\%)\end{array}$ & $\begin{array}{c}\text { Query } \\
\text { coverage }(\%)\end{array}$ & $\begin{array}{c}\text { Seq. accession } \\
\text { number }\end{array}$ \\
\hline Elg1 & Fusarium verticillioides & 90.7 & 86.4 & XM_018903492 \\
Epl1 & Alternaria alternate & 86 & 81 & XM_018523228 \\
& Alternaria arborescens & 82.2 & 87.5 & XM_028653137 \\
Epf1 & Fusarium oxysporum & 96.7 & 92 & XM_018385957 \\
& Fusarium venenatum & 85 & 82 & XM_025727897 \\
\hline
\end{tabular}

Epl1 = Endophytes from Pyrethrum leaf, Epf1 = Endophytes from Pyrethrum flower, Elg1 = Endophytes from Lemon grass

previous studies which showed possibilities of isolating these Genuses of endophytic fungi from local plants (Avinash and Krishnamurthy, 2015). The shape and structure also matched with the shape and structures of these genuses (Fig. 2).
Molecular identification. The results of this study have confirmed that all the isolates belonged to Division Ascomycota as previously shown in morphological identification (Fig. 2). According to Tidke et al. (2017), the ITS region in the fungal kingdom that had an 
G. MICHAEL et al.

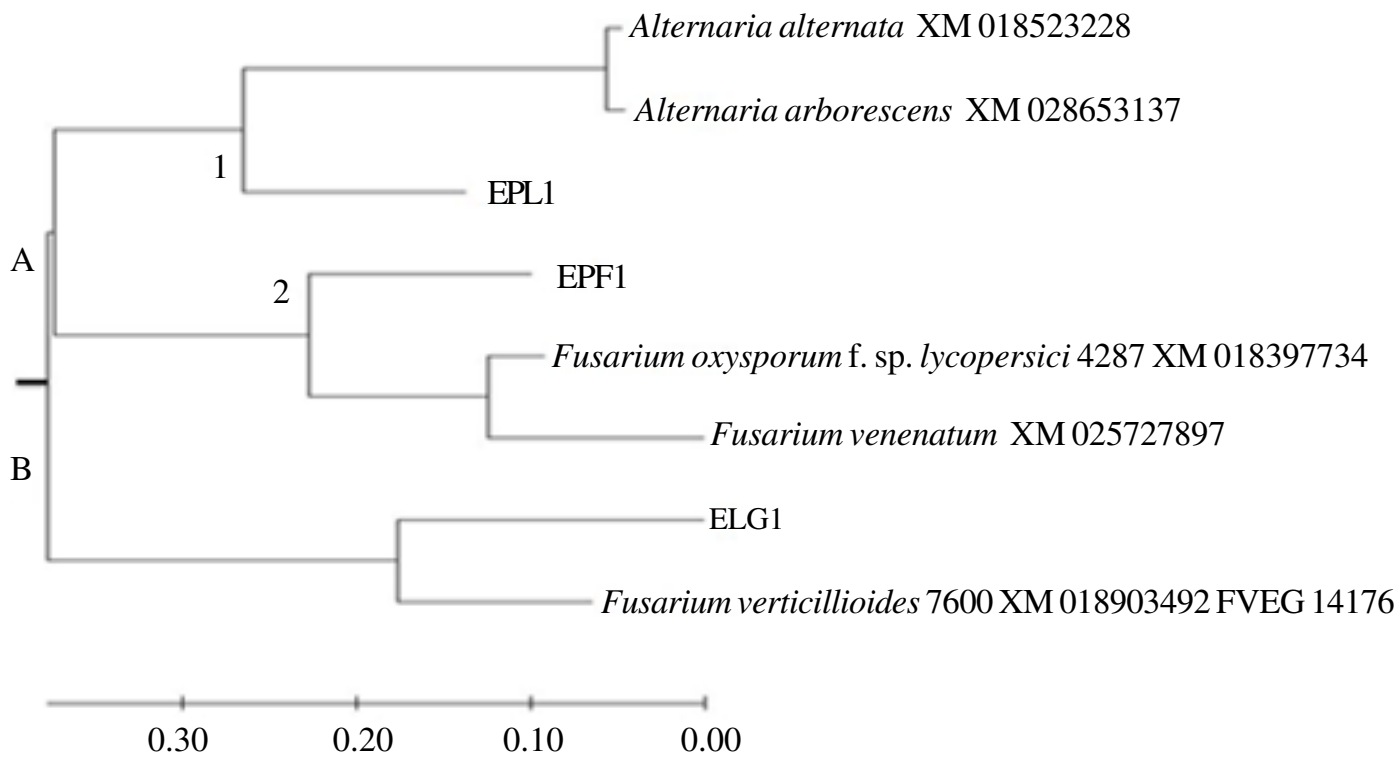

Figure 4. Phylogenetic tree three isolates and their close related fungi in The National Center for Biotechnology Information (NCBI).

TABLE 3. Proportion of whiteflies and tomato leaf miner survival (\%) on tomato seedlings treated with bio-extracts prepared from different endophytic fungal isolates

\begin{tabular}{lcccc}
\hline Endophyte isolate & \multicolumn{2}{c}{ Pest survival under repellant (R) and lethal (L) } & & Bio-extract treatments \\
\cline { 2 - 3 } & Whiteflies ( R ) & Whiteflies (L) & & Tomato leaf miner (L) \\
\hline Control & $32 \mathrm{a}$ & $95 \mathrm{a}$ & $85 \mathrm{a}$ \\
Elg1 & $13 \mathrm{bc}$ & $30 \mathrm{c}$ & $20 \mathrm{~b}$ \\
Epf1 & $8 \mathrm{c}$ & $20 \mathrm{c}$ & $5 \mathrm{~b}$ \\
Epl1 & $20 \mathrm{~b}$ & $60 \mathrm{~b}$ & $65 \mathrm{a}$ \\
\hline
\end{tabular}

Letters on same column with same letter are not significantly different at $\mathrm{P}>0.05$. Raw with $\mathrm{R}$ means repellence while L means lethality. Epl1 = Endophytes from Pyrethrum leaf, Epf1 = Endophytes from Pyrethrum flower and Elg1 = Endophytes from Lemon grass

TABLE 4. Concentration of total phenol and flavonoid in endophytic bio-extracts from lemon grass and Pyrethrum

\begin{tabular}{lccc}
\hline & $\begin{array}{c}\text { Lemon grass } \\
\left(\mathrm{mg} \mathrm{g}^{-1}\right)\end{array}$ & $\begin{array}{c}\text { Pyrethrum flowers } \\
\left(\mathrm{mg} \mathrm{g}^{-1}\right)\end{array}$ & $\begin{array}{c}\text { Pyrethrum leaves } \\
\left(\mathrm{mg} \mathrm{g}^{-1}\right)\end{array}$ \\
\hline Flavonoids & $16.8 \pm 2.9$ & $11.4 \pm 0.9$ & $8.4 \pm 1$ \\
Total phenol & $3.1 \pm 0.4$ & $1.7 \pm 0.3$ & $0.76 \pm 0.2$ \\
\hline
\end{tabular}


average length of $500-600 \mathrm{bp}$, belonged to Division Ascomycetes and Basidiomycetes (Fig. 3).

The taxonomic identities and phylogenetic relationships of fungal endophyte Epl1 showed that the isolated endophytic fungi were related to Alternaria alternata and Alternaria arborescens (Fig. 4). This result was evidence that the isolate was not exactly of the identified spicies, but had evolved from Genus Alternaria. This result concurs the results of the study by Khan et al. (2015) which isolated Alternaria sp. and Fusaria sp. as endophytes from lemon grass. Nisa et al. (2018) showed that Alternaria sp. can also colonise and has been isolated from pesticidal plants, like Artemisia sp., Melia sp. and Pyrethrum sp. This suggests that the Genus Alternaria and Fusaria endophytes are capable of colonising internal plant parts, irrespective of the type of bioactive compounds they contain.

The isolated fungal endophytes from pyrethrum flower and lemon grass leaves confirmed the endophytic fungi that were related to Genus Fusaria sp., as suggested in morphological identification (Fig. 2). The isolates from pyrethrum flower were closely related to Fusaria oxysporum and Fusarium venenatum, with the identity of more than $85 \%$ and query coverage of more than $81 \%$.

The isolates from lemon grass leaves were closely related to Fusarium verticillioides (Fig. 4). These results correspond to the results of various studies that showed Genus Fusarium to be among the dominant endophytic fungi isolated from various plants (Faeth and Fagan, 2002; Avinash and Krishnamurth, 2015). Deepthi et al. (2018) identified endophyte fungi, Fusaria sp. and Alternaria sp., as the most dominant endophyte from leaves of Elaeocarpus sphaericus (gaertn.) and Myristica fragrans. Results of phylogenic tree (Fig. 1) showed that isolates of Fusarium sp. from pyrethrum flower were closely related to Genus Alternaria sp. from pyrethrum leaves, hence grouped in same taxon, than Fusaria sp. from lemon grass.
The closeness of individuals of different genuses compared with individuals from the same Genus may be justified by adaptation and colonisation of similar micro-habitat in pyrethrum plant. The latter process has resulted into different microorganisms dominating the same micro-habitat (plant) to become more related, than similar microorganisms that harboured different plants.

Berlocher and Feder (2002) showed that geographic incorporation and natural events make organisms initiate ecological associations or allow the individuals of the same species to interbreed, hence causing more relatedness than organisms in geographical isolation with no natural events. Therefore, over time, different organisms in the same plant will be closely related to those in different plants (micro-geographical isolation).

Effectiveness of bioactive compounds. The results of this study have demonstrated the ability of endophytic bioextracts to cause significant repellency and lethality to whiteflies and leaf miner in tomato plants (Table 3). Farghaly et al. (2009) showed successful pests management of sucking insects like whiteflies in different crops, using plant extracts and essential oils. Studies also showed that endophytes of medicinal and insecticidal plants have the ability to produce bioactive compounds in their bioextracts that mimic their host plants (Rodriguez et al., 2009). This may be the reason for the lower number of pests infestations in endophytic bioextracts sprayed plants, compared to their controlled treatment. The repellence and lethality of endophytic bioextract may be due to anti-feedant and fumigative properties of secreted bioactive compound within bio extract (Cox, 2004).

Earlier studies revealed components of lemon grass and pyrethrum with repellent and insecticidal properties; the most citral ones being cineole and pyrethrine (Sinthusiri and Soonwera, 2013; Soni, 2014). The nature of quantified biochemical content which are total 
phenol and flavonoids are responsible for organoleptic properties like bitterness and astringency of plant that enhance pests deterrence or changing feeding preference.

The ability of endophytic fungi of pesticidal plants to produce effective bioactive compounds in bioextracts that can deter or kill insect pests as plants extracts, provide us the basics for obtaining novel and reliable sources biological pests control. The effectiveness of these bioactive compounds has been seen in the ability to deter and kill insect pests when they come in contact, are consumed or inhaled (Avinash and Krishnamurthy, 2015).

The poisoning nature of bioextract of lemon grass and pyrethrum has been evident in repelling (detestable by insect pests) and killing the whiteflies and tomato leaf miner within specified period of time. Production of endophytic bioextracts from pyrethrum and lemon grass may, therefore, provide us a promising way of obtaining effective bioactive compounds against tomato whiteflies and leaf miners, without necessarily cultivating the plant.

Phenolic and flavonoid compounds. This study quantified biochemical components (phenolic and flavonoid content) that are associated with insecticidal properties in endophytic bioextracts (Table 3). The amount of total phenol and flavonoid contents in endophytic bioextracts in pyrethrum flower and lemon grass were related to repellence and lethality of whiteflies and tomato leaf miner.

The mode of action of these biochemical compounds are thought to disrupt major metabolic pathways, hence cause rapid insect death when consumed; affect nervous system, act as antifeedants or modify oviposition, hence retard insect population (Njau et al., 2017).

The isolated endophytic fungi in lemon grass and pyrethrum flower (Table 3) belong to general Fusaria sp. From bioextracts of these endophytes from both lemon grass and pyrethrum flower we find higher total phenol and flavonoid contents. (Table 2). The results showed that the total phenol and flavonoid contents in lemon grass and pyrethrum flower were higher compared to those in pyrethrum leaves. The repellence and lethality properties of bioextracts from lemon grass and pyrethrum flower were more effective compared to those of bioextract of Phyrethrum leaves.

Our results concur with the results of previous studies, which showed increased amounts of total phenol and flavonoid in botanical, infested plants or endophytic bioextracts was associated with pest deterrence and resisance (Abang et al., 2016). The quantity of these biochemical components, therefore, is directly associated with repellency and lethality of whiteflies and tomato leaf miner in trial as seen in Table 3. Tintjer and Rudger (2006) also support the result by showing endophytic extracts with flavonoid and total phenol are effective to insect pests and some pathogenic bacteria and fungi.

\section{CONCLUSION}

The presence of lethal and repellant properties of endophytic fungi bioextracts from pyrethrum and lemon grass can potentially be father developed and verified for use as alternative pesticides of tomato whiteflies and leaf minors. Several bioactive ingredients are suspected, but the presence of flavonoids and total phenolic are confirmed to play a major role in the killing of tomato leaf miner larvae and whiteflies as well as repelling whiteflies. Molecular and morphological examinations revealed endophytic fungi from pyrethrum flower and leaf parts closely belonged to Genus Alternaria and Fusaria; while that in lemon grass belonged to Genus Fusaria. From a botanical standpoint, the fungi were identified as A. alternate, A. arborescens, $F$. oxysporum and $F$. venenatum for those from pyrethrum plant parts, and $F$. verticillioides from lemon grass. 


\section{ACKNOWLEDGEMENT}

The authors are grateful to the Tanzania Agriculture Research Institute (TARI), Tengeru, and The Nelson Mandela University Institute of Science and Technology, Arusha, Tanzania for technical and materials support towards this study.

\section{REFERENCES}

Abang, A.F., Srinivasan, R., Kekeunou, S., Yeboah, M., Hanna, R., Lin, M.Y., Tenkouano, A. and Bilong, C.F. 2016. Relationship of phenotypic structures and allelochemical compounds of okra (Abelmoschus spp.) toresistance against Aphis gossypii Glover. International Journal of Pest Management 62(1):55-63.

Athman, S.Y., Dubois, T., Coyne, D., Gold, C.S., Labuschagne, N. and Viljoen, A. 2007. Effect of endophytic Fusarium oxysporum on root penetration and reproduction of Radopholus similis in tissue culture-derived banana (Musa spp.). Journal of Plants Nematology 9:599-607.

Avinash, K.S. and Krishnamurthy, Y.L. 2015. Diversity of fungal endophyte communities in lemon grass (spp. growing in areas of Central Western Ghats, Karnataka, India). International Journal of Mycological Society 44:78-82.

Berlocher, S.H. and Feder, J.L. 2002. Sympatric speciation in phytophagous insects: moving beyond controversy? Annual Review of Entomology 47:773-815.

Clement, S.L., Martin, R.C., Dombrowski, J.E., Elberson, L.R., Kynaston, M. and Azevedo, M.D. 2008. Neotyphodium endophytes in tall fescue seed: Viability after seed production and prolonged cold storage. Journal of Seed Science and Technology 36:710-720.

Cox, P.D. 2004. Potential for using semiochemicals to protect stored products from insect infestation. Journal of Stored Products Research 40(1):1-25.
Deepthi, V.C., Sumathi, S., Faisal, M. and Elyas, K. K. 2018. Isolation and identification of endophytic fungi with antimicrobial activities from the leaves of Elaeocarpus sphaericus (gaertn.) k. schum. and Myristica fragrans houtt. International Journal of Pharmaceutical Sciences and Research 9:2783-2791.

Elgorban, A.M., Bahkali, A.H., Al-Farraj, D.A. and Abdel-Wahab, M.A. 2019. Natural products of Alternaria sp., an endophytic fungus isolated from Salvadora persica from Saudi Arabia. Saudi Journal of Biological Sciences 26:1068-1077.

Faeth, S.H. and Fagan, W.F. 2002. Fungal Endophytes: Common Host Plant Symbionts but Uncommon Mutualists. Journal of Integrative and Comparative Biology 42(1):360-368.

Farghaly, S.F., Torkey, H.M. and Abou-Yousef, H.M. 2009. Natural extracts and their chemical constituents in relation to toxicity against whitefly (Bemisia tabaci) and aphid (Aphis craccivora). Australian Journal of Basic and Applied Science 3(4):32173223.

Grdiša, M. and Gršiæ, K. 2013. Botanical Insecticides in Plant Protection. Journal of Agriculturae Conspectus Scientificus 78:85-93.

Khan, A.L., Hussain, J., Al-Harrasi, A., AlRawahi, A. and Lee, I.J. 2015. Endophytic fungi: Resource for gibberellins and crop abiotic stress resistance. Critical Review Biotechnology 35:62-74.

Kumar, S. and Kaushik, N. 2013. Metabolites of endophytic fungi as novel source of biofungicide: A review. Phytochemistry Review 11(4):507-522.

McKinnon, A.C., Saari, S., Moran-Diez, M.E., Meyling, N.V., Raad, M. and Glare T.R. 2017. Beauveria bassiana as an endophyte: A critical review on associated methodology and biocontrol potential. Journal of BioControl 62:1-17. 
Nair, D.N. and Padmavathy, S. 2014. Impact of endophytic microorganisms on plants, environment and humans. Scientiûc World Journal 6:1-11.

Nisa, H., Kamili, A.N., Nawchoo, I.A., Bhat, M.S. and Nazir, R. 2018. Isolation and identification of endophytic fungi from Artemisia scoparia (Asteraceae). International Journal of Theoretical and Applied Sciences 10(1):83-88.

Njau, G.M., Nyomora, A.M.S., Dinssa, F.F., Chang, J.C. and Srinivasan, R. 2017. Evaluation of onion (Allium cepa) germplasm entries for resistance to onion thrips, Thrips tabaci (Lindeman) in Tanzania. International Journal of Tropical Insects Science 37(1):98-113.

Pinto, Z.T., Sánchez, F.F., Santos, A.R., Amaral, A.C.F., Ferreira, J.L.P., EscalonaArranz, J.C. and Queiroz, M.M.C. 2015. Chemical composition and insecticidal activity of Cymbopogon citratus essential oil from Cuba and Brazil against housefly. Brazilian Journal of Veterinary Parasitology 24(2):36-44.

Rodriguez, R.J., White, J.F., Arnold, A.E. and Redman, R.S. 2009. Fungal endophytes: Diversity and functional roles. New Phytologist Journal 182(2):314-330.
Shawkat, M.S., Khazaal, A.Q. and Majeed, R.M. 2011. Extraction of pyrethrins from Chrysanthemum cinerariaefolium petals and study its activity against beetle flour Tribolium castanum. Iraqi Journal of Science 52(6):456-463.

Singh, K., Frisvad, J.C., Thrane, U. and Mathur, B.S. 1991. An illustrated mycological manual on identification of Aspergilli sp., Fusaria sp. Penicillia sp. AiO Tryk, Odense, Denmark. pp. 63-70

Sinthusiri, J. and Soonwera, M. 2013. Efficacy of herbal essential oils as insecticides against the housefly, Musca domestica $\mathrm{L}$. Southeast Asian Journal of Tropical Medical Public Health 44(2):188-196.

Soni, V. 2014. Use of pyrethrin/pyrethrum and its effect on environment and human: $A$ Review. PharmaTutor Magazine 2(6):5260.

Tintjer, T. and Rudger, A.J. 2006. Grassherbivore interaction altered by strains of a native endophyte. New Phytologist 170(3): 513-521.

Yee, W., Abdul Kadir, R., Lee, L.M., Koh, B., Lee, Y.S. and Chan, H.Y. 2018. A simple and inexpensive physical lysis method for DNA and RNA extraction from freshwater microalgae. Journal of Biotechnology 28(4):354-361. 